\title{
Efficacy of Brentuximab Vedotin in Relapsed or Refractory High-CD30-Expressing Non-Hodgkin Lymphomas: Results of a Multicenter, Open-Labeled Phase II Trial
}

\author{
Seok Jin Kim, MD, PhD ${ }^{1}$ \\ Dok Hyun Yoon, MD, PhD² \\ Jin Seok Kim, MD, PhD ${ }^{3}$ \\ Hye Jin Kang, MD, $P h D^{4}$ \\ Hye Won Lee, MD, PhD ${ }^{5}$ \\ Hyeon-Seok Eom, MD, PhD \\ Jung Yong Hong, $\mathrm{MD}, \mathrm{PhD}{ }^{2}$ \\ Junhun Cho, MD, PhD \\ Young Hyeh Ko, MD, $\mathrm{PhD}^{6}$ \\ Jooryung Huh, MD, $\mathrm{PhD}^{7}$ \\ Woo-Ick Yang, MD, PhD \\ Weon Seo Park, MD, PhD 9 \\ Seung-Sook Lee, MD, PhD'10 \\ Cheolwon Suh, MD, PhD² \\ Won Seog Kim, MD, PhD ${ }^{1}$
}

${ }^{*} A$ list of author's affiliations appears at the end of the paper.

\author{
Correspondence: Won Seog Kim, MD, PhD \\ Division of Hematology-Oncology, \\ Department of Medicine, Samsung Medical \\ Center, Sungkyunkwan University School of \\ Medicine, 81 Irwon-ro, Gangnam-gu, \\ Seoul 06351, Korea \\ Tel: $82-2-3410-6548$ \\ Fax: 82-2-3410-1754 \\ E-mail: wskimsmc@skku.edu \\ Received April 12, 2019 \\ Accepted August 12, 2019 \\ Published Online August 13, 2019
}

\begin{abstract}
Purpose
The treatment outcome of brentuximab vedotin (BV) has not been related with CD30 expression in previous studies enrolling patients with a wide range of CD30 expression level. Thus, this study explored the efficacy of BV in high-CD30-expressing non-Hodgkin lymphoma (NHL) patients most likely to benefit.
\end{abstract}

\section{Materials and Methods}

This phase II study (Clinicaltrials.gov: NCT02280785) enrolled relapsed or refractory highCD30-expressing NHL, with BV administered intravenously at $1.8 \mathrm{mg} / \mathrm{kg}$ every 3 weeks. The primary endpoint was $>40 \%$ disease control rate, consisting of complete response (CR), partial response (PR), or stable disease. We defined high CD30 expression as $\geq 30 \%$ tumor cells positive for CD30 by immunohistochemistry.

\section{Results}

High-CD30-expressing NHL patients $(n=33)$ were enrolled except anaplastic large cell lymphoma. The disease control rate was $48.5 \%$ (16/33) including six CR and six PR; six patients (4CR, 2PR) maintained their response over 16 completed cycles. Response to BV and survival were not associated with CD30 expression levels. Over a median of 29.2 months of follow-up, the median progression-free and overall survival rates were 1.9 months and 6.1 months, respectively. The most common adverse events were fever (39\%), neutropenia (30\%), fatigue (24\%), and peripheral sensory neuropathy (27\%). In a post-hoc analysis for the association of multiple myeloma oncogene 1 (MUM1) on treatment outcome, MUM1negative patients showed a higher response $(55.6 \%, 5 / 9)$ than MUM1-positive patients (13.3\%, 2/15).

\section{Conclusion}

BV performance as a single agent was acceptable in terms of disease control rates and toxicity profiles, especially MUM1-negative patients.

\section{Introduction}

Brentuximab vedotin (BV) is an anti-CD30 monoclonal antibody conjugated with the microtubule-disrupting agent monomethyl auristatin E [1]. CD30, a transmembrane glycoprotein, is uniformly expressed in Hodgkin lymphoma (HL) and anaplastic large cell lymphoma (ALCL). BV has been previously approved for the treatment of relapsed or refrac-
Key words

Brentuximab vedotin, Non-Hodgkin lymphoma, CD30,

Multiple myeloma oncogene-1 tory HL and systemic ALCL based on its high objective response rates of $75 \%$ and $86 \%$ in relapsed or refractory HL and systemic ALCL, respectively [2,3]. Subsequent to that approval, the efficacy of BV was evaluated in various subtypes of non-Hodgkin lymphoma (NHL), including diffuse large B-cell lymphoma (DLBCL), primary mediastinal B-cell lymphoma (PMBCL), peripheral T-cell lymphoma (PTCL), mycosis fungoides $(\mathrm{MF})$, and various cutaneous T-cell lymphomas [4-8]. All of these studies enrolled patients with a wide range 
of CD30 expression levels, and their response rates were unrelated to CD30 expression level of tumor cells. For example, $70 \%$ of patients with cutaneous T-cell lymphomas, including MF, responded to BV, and the different cutoff values $(<10 \%, 10 \%-50 \%$, and $\geq 50 \%)$ were unrelated to response rate in $\mathrm{MF}$, although patients with $<5 \% \mathrm{CD} 30$ expression had a lower response likelihood compared with patients with $\geq 5 \%$ expression $[4,5]$. The response rate to $\mathrm{BV}$ was also unrelated with the level of CD30 expression in DLBCL (44\%) and PTCL $(41 \%)$, and these response rates were higher in PMBCL patients $(13.3 \%)$ even though PMBCL is typically characterized by high CD30 expression [6-8]. Accordingly, these previous studies enrolling patients with a wide range of CD30 expression levels may not provide sufficiently robust information on the association between CD30 expression and response to $B V$. Thus, we designed a phase II study to evaluate the efficacy of BV as a salvage therapy in relapsed or refractory patients with high-CD30-expressing NHL other than ALCL. Although a precise definition of high CD30 expression has not been established, we defined cases having $\geq 30 \%$ of CD30-positive tumor cells as high-CD30-expressing NHL considering previous studies have used $10 \%$ to $20 \%$ of CD30positive tumor cells as the cutoff values for $\mathrm{CD} 30$ expression across various subtypes of NHL [9-12].

CD30, a member of the tumor necrosis factor receptor superfamily, is known to exert a variety of biological functions, including cell cycle regulation, apoptosis, and activation of nuclear factor $\kappa$-light-chain-enhancer of activated B cells (NF-kB). CD30 is preferentially expressed in activated $\mathrm{B}$ cells; however, $\mathrm{T}$ and natural killer (NK) cells are also reported to express CD30 [13]. In addition, Epstein-Barr virus (EBV) infection-associated lymphomas could express CD30 because latent membrane protein 1, a critical element of EBV infection, may promote CD30 expression [14]. Accordingly, previous studies have shown approximately $40 \%$ of CD30 expression in extranodal natural killer/T-cell lymphoma (ENKTL), in which latent membrane protein 1 is commonly expressed $[15,16]$. CD30 expression is also associated with activation of interferon regulatory factor 4 , also known as multiple myeloma oncogene 1 (MUM1), because CD30 activation may promote activities of the NF-kB leading to MUM1 expression [17]. This positive feedback signaling from CD30 to MUM1 might contribute to tumor aggressiveness, because MUM1 binds directly to the MYC promoter region leading to cell proliferation $[18,19]$. Thus, EBV positivity and MUM1 expression of lymphoma cells may influence response to BV due to their close relationship with CD30 expression.

We analyzed response rates in accordance with CD30 positivity and presented the results of this study after the completion of enrollment at the annual meeting of American Society of Hematology in 2017 [20]. For this final report, we re-evaluated the pathology subtypes and performed the post- hoc analysis evaluating the associations of EBV positivity and MUM1 expression with response to BV and survival outcome to find biomarkers. We also re-evaluated the treatment response to determine the interpatient heterogeneity of response as a post-hoc analysis, and updated the survival status on November 30, 2018.

\section{Materials and Methods}

\section{Study design}

This phase 2, open-label, multicenter study was designed to evaluate the efficacy and safety of BV in patients with relapsed or refractory high-CD30-expressing NHL other than ALCL. All subtypes of NHL including mature B-, T-, or NKcell lymphomas except ALCL were eligible for enrollment. Because all patients were initially diagnosed with NHL before 2017, NHL subtype was classified based on the World Health Organization's 2008 criteria. The primary study objective was to determine the overall rate of disease control, defined as complete response (CR), partial response (PR), and stable disease (SD). Secondary objectives included determining toxicity profiles, progression-free survival (PFS), and overall survival (OS). Patients received $1.8 \mathrm{mg} / \mathrm{kg}$ BV intravenously every 3 weeks. Those who achieved SD or better continued to receive treatments up to a maximum of 16 cycles. However, in the event of progressive disease (PD) or unacceptable toxicity, BV administration should be discontinued; dose reduction to $1.2 \mathrm{mg} / \mathrm{kg}$ and treatment delay up to 3 weeks was allowed, depending on the type and severity of toxicity, including peripheral neuropathy. Blood transfusion or granulocyte colony-stimulating factors were allowed for patients with anemia, thrombocytopenia, and neutropenia. Response evaluation was completed by the investigator according to the 2007 Revised International Working Group Response Criteria for Malignant Lymphoma [21]. Baseline assessment was performed by using computed tomography (CT) and fluorine-18 deoxyglucose (FDG) positron emission tomography/computed tomography (PET/CT) of the neck, chest, abdomen, and pelvis prior to the first treatment cycle. Restaging assessment was performed by CT and PET/CT after the second cycle. Additional response evaluations for preexisting lesions were evaluated after the fourth, eighth, twelfth, and sixteenth cycles by CT scan. For apparently new lesions unobserved on pretreatment or other posttreatment scans, PET/CT was performed to confirm disease progression. Toxicity was assessed from the first dose to 4 weeks following the last BV dose and adverse events were graded using ver. 4.0.3 of the National Cancer Institute Common 
Terminology Criteria for Adverse Events. Assessment of disease and survival status took place every 3 months per institutional standards of care and thereafter until study closure or withdrawal of consent for patients who received at least one dose of BV.

\section{Eligibility}

There were five eligibility criteria. (1) Any subtype of histologically confirmed high-CD30-expressing NHL, except ALCL. High CD30 expression was defined as membranous CD30 expression in $\geq 30 \%$ of tumor cells detectable by visual assessment of routine immunohistochemistry staining using the anti-CD30 antibody on biopsy at the time of diagnosis or relapse. (2) A bidimensionally measurable lesion $\geq 1.5 \mathrm{~cm}$ in the greatest transverse diameter. (3) Age 20-75 years and an Eastern Cooperative Oncology Group performance status of $\leq 2$. (4) Adequate bone marrow and organ function. (5) No history of another active cancer within the previous 5 years except basal cell carcinoma. Note that patients who had relapsed after autologous stem cell transplantation (SCT) were considered eligible. Exclusion criteria were: undergoing allogeneic SCT; active infection, human immunodeficiency virus infection, or hepatitis B or C; and lymphomatous involvement of the central nervous system. The $30 \%$ cutoff was established by consensus during an investigation initiation meeting of the pathologists from each of the study sites after they reviewed various cutoff values for 'positive' and 'strong positive' of CD30 expression across various subtypes of NHL [4-12].

\section{Statistical analysis}

Sample size was calculated to reject the null with a $20 \%$ overall disease control rate but increased to favor of a target rate of $40 \%$ with significance 0.05 and power $80 \%$ using Simon's Minimax two-stage design [22]. Thus, if the rate was less than $4 / 18$ during the first stage, the study would be stopped. If not, patient recruitment would be continued until $\mathrm{n}=33$. Patients' clinical characteristics, demographics, and treatment outcomes were analyzed based on the NHL subtype, and chi-squared tests were used to evaluate their relationships with outcomes. OS was calculated from the first date of BV infusion to final follow-up or death from any cause. PFS was calculated from the first date of BV infusion to the date of disease progression or death from any cause. Median potential follow-up time with $95 \%$ confidence interval (CI) was determined using the Kaplan-Meier method [23]. Survival was estimated based on Kaplan-Meier curves and compared using the log-rank test. Two-sided $\mathrm{p}<0.05$ was considered statistically significant.

\section{Biomarker analysis}

Quantified CD30 expression from tumor cells was compared with determined response to BV. Immunohistochemistry was performed on $4-\mu \mathrm{m}$ paraffin sections following routine protocols using a fully automated platform at each institute; CD30 was detected using a ready-to-use antibody (clone BerH2, Dako, Carpinteria, CA). EBV in situ hybridization and MUM1 expression were analyzed in patients who had tissue sample available for analysis. The presence of EBV-positive tumor cells was considered EBV positivity regardless of its percentage whereas MUM1-positivity was defined as more than $30 \%$ of tumor cells were positively stained. Immunohistochemistry for MUM1 (MUM1p, Dako) was also performed for exploratory biomarker development. Differences in biomarkers between responder subgroups were compared via post-hoc analysis using the chi-square test.

\section{Ethical statement}

The study was conducted by the Consortium for Improving Survival of Lymphoma (CISL) in compliance with the Declaration of Helsinki and the International Conference on Harmonization Good Clinical Practice. The Korean Food and Drug Administration approved this study (No. 30229), and each study site obtained approval from their local institutional review board. All patients gave written informed consent prior to study participation. The study was registered at ClinicalTrials.gov (NCT02280785).

\section{Results}

\section{Patients}

In total, 33 patients were enrolled between March 2015 and January 2017 from five hospitals belonged to the CISL. Their median age at enrollment was 56 years (range, 27 to 73 years); other characteristics at enrollment are summarized in Table 1. Stage III/IV patients accounted for 79\% (26/33) of the sample and $70 \%$ had elevated levels of serum lactate dehydrogenase. All patients were treated with at least one line of salvage chemotherapy. The median number of prior therapies was three (range, 2 to 10) and seven patients relapsed after autologous SCT. At enrollment, 10 patients had relapsed after their last chemotherapy and 22 were refractory after previous treatment (Table 1). The most common subtypes were DLBCL $(\mathrm{n}=12)$ including one patient with relapsed DLBCL who was initially diagnosed with angioimmunoblastic T-cell lymphoma (AITL) and peripheral T-cell lym- 
Table 1. Patient characteristics at enrollment

\begin{tabular}{|c|c|}
\hline Characteristic & No. $(\%)$ \\
\hline \multicolumn{2}{|l|}{ Age (yr) } \\
\hline$\leq 60$ & $23(69.7)$ \\
\hline$>60$ & $10(30.3)$ \\
\hline \multicolumn{2}{|l|}{ Sex } \\
\hline Male & $16(48.5)$ \\
\hline Female & $17(51.5)$ \\
\hline \multicolumn{2}{|l|}{ ECOG PS } \\
\hline 0 & $16(48.5)$ \\
\hline 1 & $17(51.5)$ \\
\hline \multicolumn{2}{|l|}{ Ann Arbor stage } \\
\hline Stage I/II & $1 / 6(21.2)$ \\
\hline Stage III/ IV & $7 / 19(78.8)$ \\
\hline \multicolumn{2}{|l|}{ B symptoms } \\
\hline Absence & $27(81.8)$ \\
\hline Presence & $6(18.2)$ \\
\hline \multicolumn{2}{|l|}{ Serum LDH } \\
\hline Normal & $10(30.3)$ \\
\hline Increased & $23(69.7)$ \\
\hline \multicolumn{2}{|l|}{$\beta 2$ microglobulin } \\
\hline Normal & $9(27.3)$ \\
\hline Increased & $24(72.7)$ \\
\hline \multicolumn{2}{|c|}{ Autologous stem cell transplantation } \\
\hline Done & $7(21.2)$ \\
\hline Not done & $26(78.8)$ \\
\hline \multicolumn{2}{|c|}{ No. of previous treatments } \\
\hline$\leq 3$ & $24(72.7)$ \\
\hline$>3$ & $9(27.3)$ \\
\hline \multicolumn{2}{|l|}{ Disease status } \\
\hline Relapsed & $11(33.3)$ \\
\hline Refractory & $22(66.7)$ \\
\hline \multicolumn{2}{|l|}{ Subtype } \\
\hline DLBCL & $12(36.4)$ \\
\hline PMBCL & $3(9.0)$ \\
\hline PTCL-NOS & $8(24.2)$ \\
\hline ENKTL & $7(21.2)$ \\
\hline AITL & $1(3.0)$ \\
\hline Transformed MF & $2(6.0)$ \\
\hline \multicolumn{2}{|l|}{ CD30 expression $(\%)$} \\
\hline $30-49$ & $13(39.4)$ \\
\hline $50-79$ & $9(27.3)$ \\
\hline $80-100$ & $11(33.3)$ \\
\hline
\end{tabular}

ECOG PS, Eastern Cooperative Oncology Group performance status; $\mathrm{LDH}$, lactate dehydrogenase; DLBCL, diffuse large B-cell lympho-ma; PMBCL, primary mediastinal large B-cell lymphoma; PTCL-NOS, peripheral T-cell lymphoma not otherwise specified; ENKTL, extranodal NK/ T-cell lymphoma; AITL, angioimmunoblastic T-cell lymphoma; MF, mycosis fungoides. phoma not otherwise specified (PTCL-NOS; $\mathrm{n}=8$ ); other subtypes included ENKTL $(\mathrm{n}=7)$, PMBCL $(\mathrm{n}=3)$, transformed MF $(\mathrm{n}=2)$, and AITL $(\mathrm{n}=1)$. The median percentage of CD30-positive tumor cells was 50\% (range, 30\% to $100 \%$ ), and $60 \%$ of patients $(\mathrm{n}=20)$ had $\geq 50 \%$ of CD30 expression (Table 1$)$.

\section{Efficacy}

Twelve patients achieved CR $(n=6)$ or PR $(n=6)$ and four patients' best response was SD; thus, the overall disease control rate was $48.5 \%$ (16/33). However, the remaining 17 patients were dropped due to early progressive disease after the first or second BV cycle. Among 12 patients with CR or PR, six (4CR, 2PR) completed 16 cycles, maintaining their response, whereas the others showed disease progression during treatment (Fig. 1A). A 70-year-old female patient with PTCL-NOS discontinued the treatment because she developed a stroke prior to her second cycle. Although her response evaluation showed SD, she could not receive further treatment. The waterfall plot for responders showed a significant change from baseline tumor size compared to nonresponders (Fig. 1B). The median number of treatment cycles was two (range, 1 to 16), however, the median cycle number for the 16 patients with CR, PR, or SD was 7.5. The overall rates of disease control in patients with DLBCL $(2 \mathrm{CR}, 2 \mathrm{PR}$, 2SD; 6/12, 50\%), PTCL-NOS (2CR, 1PR, 2SD; 5/8, 62.5\%), and transformed MF (2PR; $2 / 2,100 \%)$ were higher compared with those with ENKTL (1CR, 1PR; 2/7, 29\%), PMBCL (1CR; $1 / 3,33 \%)$, and AITL $(0 / 1,0 \%)$ albeit with small subtype samples (Fig. 2A). When response to BV was compared based on disease status prior to $B V$, there was no significant difference between patients with relapsed (3CR, 2PR, 1SD; 6/11, 54.5\%) and refractory disease (3CR, 4PR, 3SD; 10/22, 45.5\%, $\mathrm{p}=0.721$ ).

\section{CD30 expression in responding patients}

Although we only enrolled patients with high-CD30expressing NHL, this sample had a wide range of CD30 expression values $(30 \%-100 \%)$. Based on their percentage of CD30-positive tumor cells, patients were grouped as 30\%$49 \%(n=13), 50 \%-79 \%(n=9)$, or $80 \%-100 \%(n=11)$. The number of patients with CR and PR did not differ significantly based on these groupings $(46 \%, 6 / 13$ vs. $11 \%, 1 / 9$ vs. $46 \%$, $5 / 11 ; \mathrm{p}=0.182$ ) (Fig. 2B). Nor did overall disease control rate differ $(46 \%, 6 / 13$ vs. $22 \%, 2 / 9$ vs. $64 \%, 7 / 11 ; \mathrm{p}=0.180)$. Although transformed MF ( $\mathrm{n}=2$; patients 25 and 26) showed 90\% and 100\% CD30 expression, respectively, their best response was PR and was not durable (Fig. 1). No other subtypes showed a significant association between CD30 expression and response to $\mathrm{BV}$. 


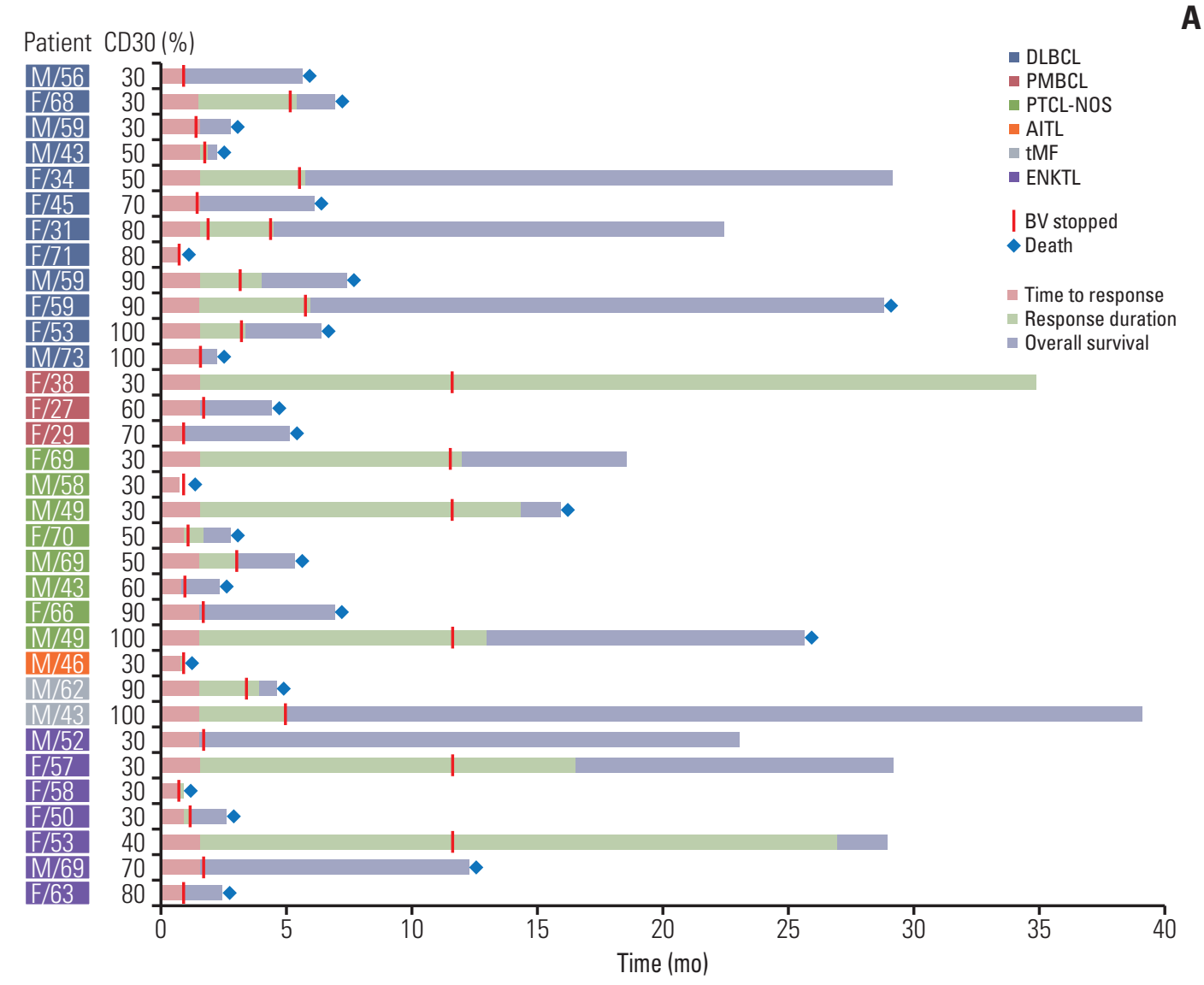

B

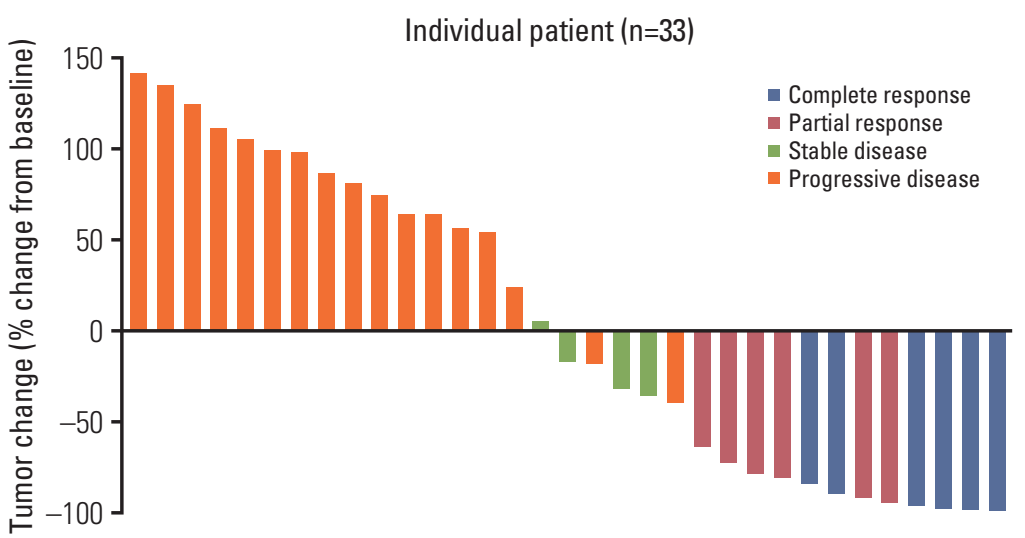

Fig. 1. (A) Swimmer plot for clinical course and duration of response in all patients. (B) Waterfall plot of percent change from baseline tumor size in all patients. DLBCL, diffuse large B-cell lymphoma; PMBCL, primary mediastinal B-cell lymphoma; PTCL-NOS, peripheral T-cell lymphoma not otherwise specified; AITL, angioimmunoblastic T-cell lymphoma; tMF, transformed mycosis fungoides; ENKTL, extranodal natural killer/T-cell lymphoma; BV, brentuximab vedotin.

\section{Survival outcome}

With a median follow-up of 29.2 months (95\% CI, 28.7 to 29.7 months), eight patients were alive and their best res- ponses were 4CR, 3PR, and 1PD. Among these, two patients (patients Nos. 13 and 16) maintained CR without any evidence of disease relapse. Five responders (2CR, 3PR) showed relapse or disease progression during treatment or after com- 

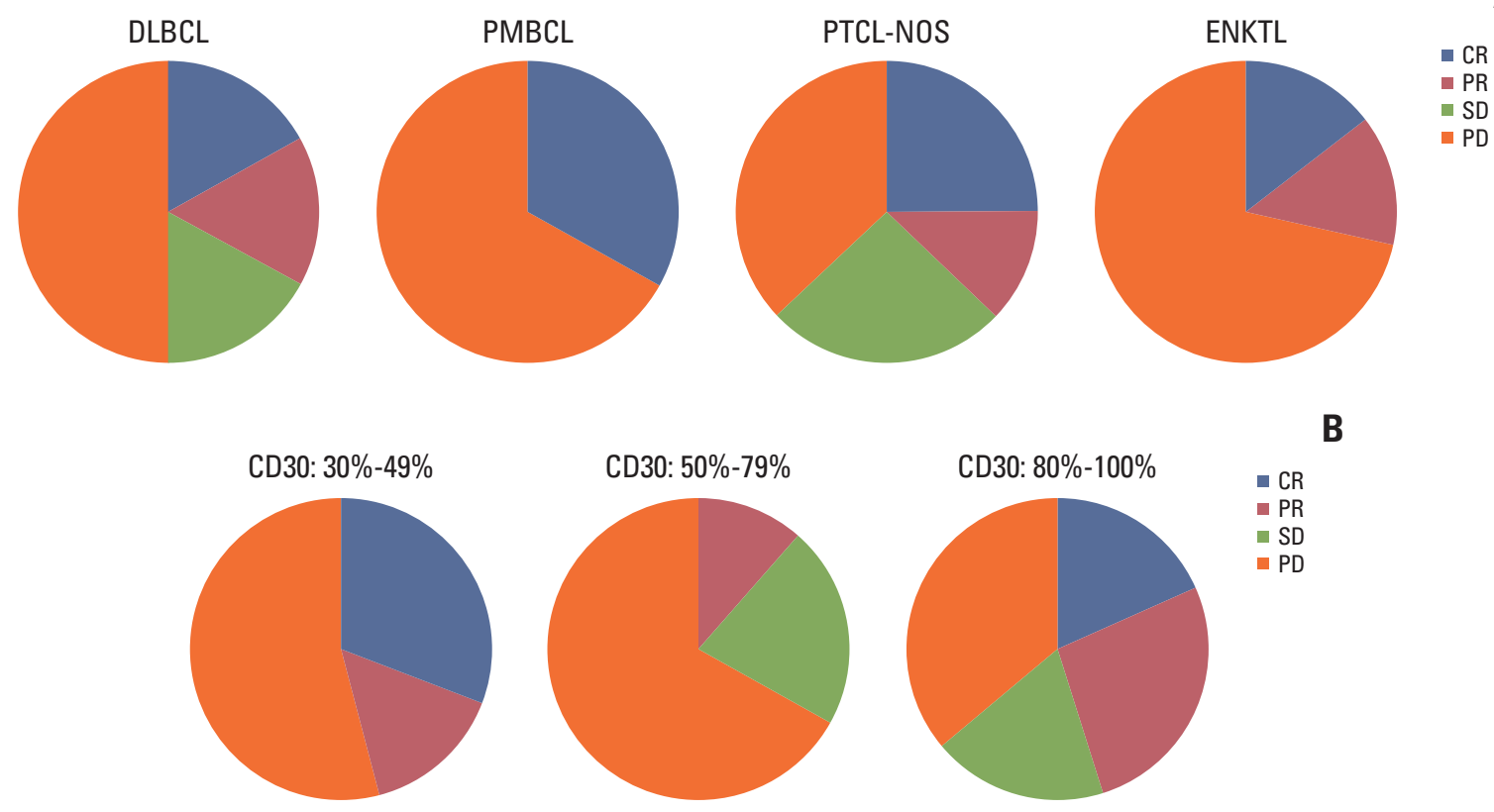

B

C
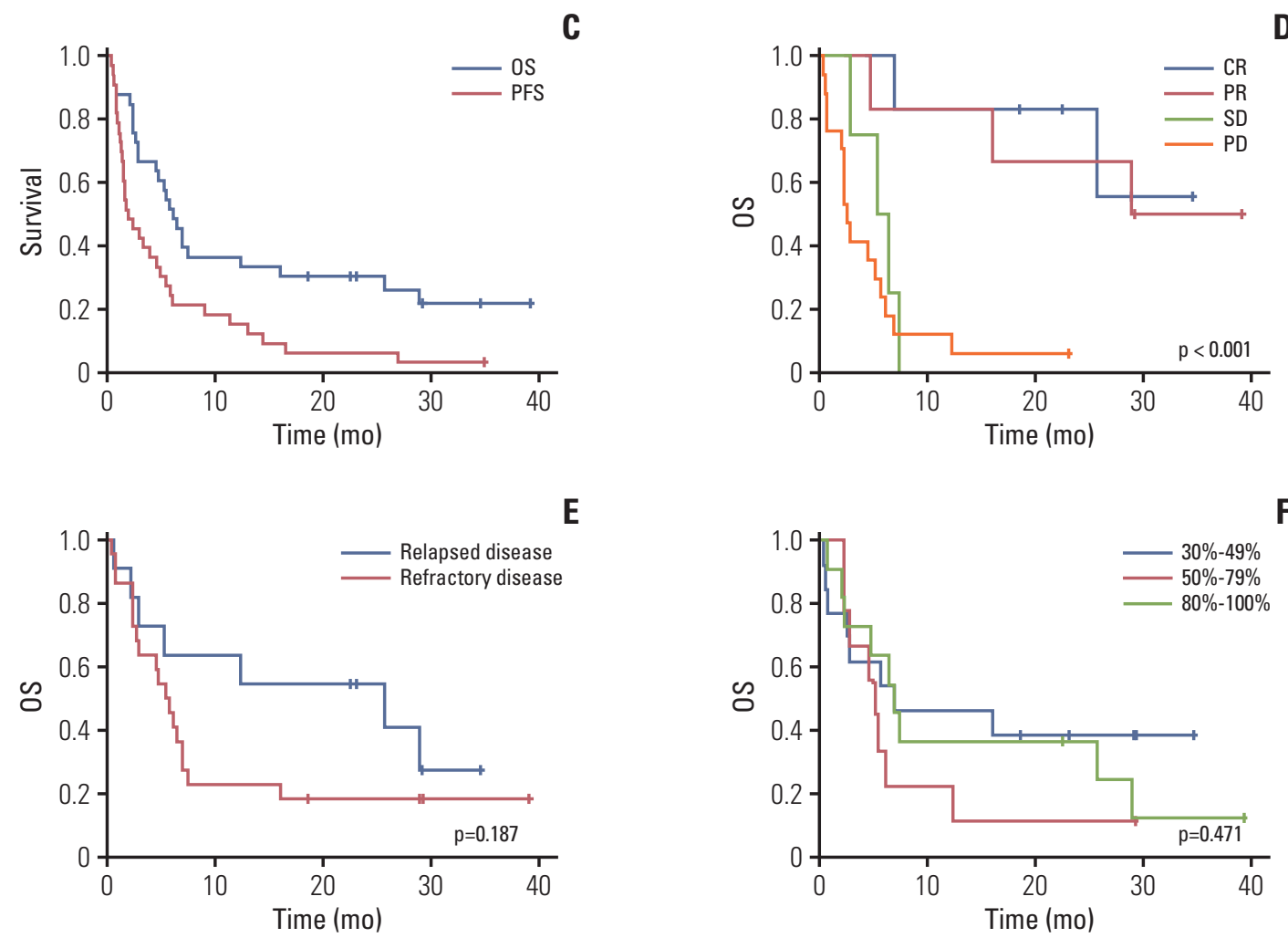

E

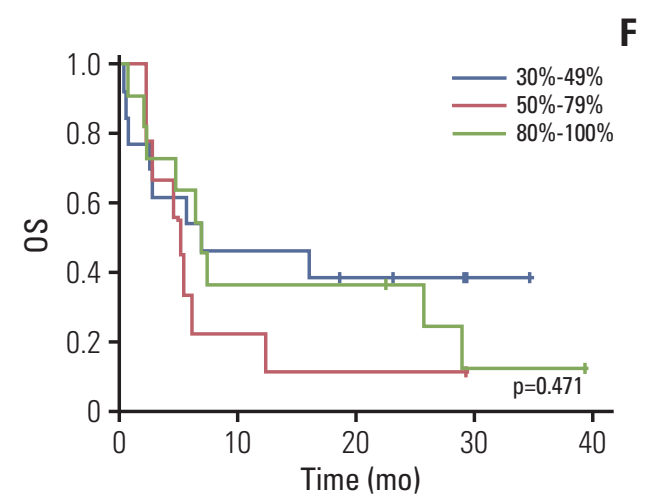

Fig. 2. (A) Response within each subtype. (B) Comparison of response based on percentage of CD30-positive tumor cells. (C) Progression-free survival (PFS) and overall survival (OS) for 33 patients. (D) OS between responders and nonresponders. (E) OS between relapsed and refractory patients. (F) OS based on percentage of CD30-positive tumor cells. DLBCL, diffuse large B-cell lymphoma; PMBCL, primary mediastinal B-cell lymphoma; PTCL-NOS, peripheral T-cell lymphoma not otherwise specified; ENKTL, extranodal natural killer/T-cell lymphoma; CR, complete response; PR, partial response; SD, stable disease; $\mathrm{PD}$, progressive disease. 
Table 2. Adverse events

\begin{tabular}{|c|c|c|c|}
\hline \multirow{2}{*}{ Adverse event } & \multicolumn{3}{|c|}{ Safety analysis population $(n=33)$} \\
\hline & Total & Grade $1 / 2$ & Grade 3/4 \\
\hline \multicolumn{4}{|l|}{ Most common adverse events $(\geq 20 \%)$} \\
\hline Fever & $13(39.3)$ & $9 / 3(36.3)$ & $1 / 1(6.0)$ \\
\hline Neutrophil count decreased & $10(30.3)$ & & $3 / 7(30.3)$ \\
\hline Peripheral sensory neuropathy & $9(27.3)$ & $8 / 1(27.3)$ & \\
\hline Fatigue & $8(24.2)$ & $2 / 3(15.1)$ & $3 / 0(9.1)$ \\
\hline Nausea & $7(21.2)$ & $2 / 3(15.1)$ & $2 / 0(6.0)$ \\
\hline Platelet count decreased & $7(21.2)$ & $1 / 0(3.0)$ & $2 / 4(18.2)$ \\
\hline Abdominal pain & $7(21.2)$ & $2 / 3(15.1)$ & $2 / 0(6.0)$ \\
\hline \multicolumn{4}{|l|}{ Common adverse events $(\geq 10 \%)$} \\
\hline Diarrhea & $6(18.1)$ & $3 / 3(18.1)$ & - \\
\hline Vomiting & $6(18.1)$ & $2 / 3(15.1)$ & $1 / 0(3.0)$ \\
\hline Anorexia & $6(18.1)$ & $2 / 3(15.1)$ & $1 / 0(3.0)$ \\
\hline Edema (facial, periorbital, or leg) & $5(15.1)$ & $2 / 2(12.1)$ & $1 / 0(3.0)$ \\
\hline Myalgia & $5(15.1)$ & $2 / 3(15.1)$ & - \\
\hline Skin rash & $5(15.1)$ & $2 / 2(12.1)$ & $1 / 0(3.0)$ \\
\hline Anemia & $4(12.1)$ & $0 / 1(3.0)$ & $3 / 0(9.1)$ \\
\hline Rhinosinusitis & $4(12.1)$ & $0 / 3(9.1)$ & $1 / 0(3.0)$ \\
\hline Upper respiratory infection & $4(12.1)$ & $2 / 2(12.1)$ & - \\
\hline ALT/AST increased & $4(12.1)$ & $2 / 0(6.0)$ & $1 / 1(6.0)$ \\
\hline Pruritus & $4(12.1)$ & $2 / 2(12.1)$ & - \\
\hline \multicolumn{4}{|l|}{ Less common events $(\geq 5 \%)$} \\
\hline Dyspnea & $3(9.0)$ & $1 / 1(6.0)$ & $1 / 0(3.0)$ \\
\hline Sore throat & $3(9.0)$ & $1 / 2(9.0)$ & - \\
\hline Cough & $3(9.0)$ & $1 / 2(9.0)$ & - \\
\hline Febrile neutropenia & $2(6.0)$ & & $2 / 0(6.0)$ \\
\hline Abdominal distension & $2(6.0)$ & $1 / 1(6.0)$ & - \\
\hline Oral mucositis & $2(6.0)$ & $1 / 0(3.0)$ & $1 / 0(3.0)$ \\
\hline Herpes zoster & $2(6.0)$ & $1 / 1(6.0)$ & - \\
\hline Creatinine increased & $2(6.0)$ & $1 / 1(6.0)$ & - \\
\hline Back pain & $2(6.0)$ & $0 / 1(3.0)$ & $1 / 0(3.0)$ \\
\hline Neck pain & $2(6.0)$ & $1 / 1(6.0)$ & - \\
\hline Dizziness & $2(6.0)$ & $1 / 1(6.0)$ & - \\
\hline Headache & $2(6.0)$ & $1 / 1(6.0)$ & - \\
\hline Urinary frequency & $2(6.0)$ & $1 / 1(6.0)$ & - \\
\hline Laryngospasm & $2(6.0)$ & $0 / 2(6.0)$ & - \\
\hline Anxiety/Depressive mood & $2(6.0)$ & & $2 / 0(6.0)$ \\
\hline Chest pain & $2(6.0)$ & $1 / 0(3.0)$ & $1 / 0(3.0)$ \\
\hline
\end{tabular}

(Continued to the next page)

pletion of 16 cycles; however, they were alive because of rescue by subsequent chemotherapies, including one case of transformed MF (patient 26) who received allogeneic SCT (Fig. 1). The one patient with ENKTL showing early PD (patient 27) was alive after responding to salvage treatments. Thus, the median duration of objective response (CR and PR) was 6.0 months (range, 3.9 to 35.0 months). However, the remaining patients died and the majority showed early PD after the first or second cycle of BV. As a result, the median PFS and OS for all patients were 1.9 months $(95 \% \mathrm{CI}, 0.6$ to 3.2 months) and 6.1 months (95\% CI, 4.5 to 7.7 months), respectively (Fig. 2C). OS among patients responding to $\mathrm{BV}$ was significantly better than that of patients with SD or PD (Fig. 2D). Although not statistically significant, the survival outcome among patients who were refractory to previous treatments prior to $\mathrm{BV}$ was inferior to that of patients with 
Table 2. Continued

\begin{tabular}{|c|c|c|c|}
\hline \multirow{2}{*}{ Adverse event } & \multicolumn{3}{|c|}{ Safety analysis population $(\mathrm{n}=33)$} \\
\hline & Total & Grade 1/2 & Grade 3/4 \\
\hline \multicolumn{4}{|c|}{ Rare events ( 1 case reported) } \\
\hline Constipation & $1(3.0)$ & $0 / 1(3.0)$ & \\
\hline Dyspepsia & $1(3.0)$ & $0 / 1(3.0)$ & \\
\hline Hemorrhoid bleeding & $1(3.0)$ & $1 / 0(3.0)$ & \\
\hline Perianal abscess & $1(3.0)$ & $0 / 1(3.0)$ & \\
\hline Gout & $1(3.0)$ & $1 / 0(3.0)$ & \\
\hline Urinary tract infection & $1(3.0)$ & & $1 / 0(3.0)$ \\
\hline Hypocalcemia & $1(3.0)$ & $0 / 1(3.0)$ & \\
\hline Stroke & $1(3.0)$ & & $1 / 0(3.0)$ \\
\hline Insomnia & $1(3.0)$ & $0 / 1(3.0)$ & \\
\hline Suicide attempt & $1(3.0)$ & & $0 / 1(3.0)$ \\
\hline Hoarseness & $1(3.0)$ & $1 / 0(3.0)$ & \\
\hline Pneumonia & $1(3.0)$ & & $1 / 0(3.0)$ \\
\hline Phlebitis & $1(3.0)$ & $0 / 1(3.0)$ & \\
\hline
\end{tabular}

Values are presented as number (\%). ALT, alanine transaminase; AST, aspartate aminotransferase.

relapsed disease after a previous treatment (Fig. 2E). However, OS did not differ based on CD30 expression (30\%-49\% vs. 50\%-79\% vs. $\geq 80 \%$ ) (Fig. 2F). Nor did OS differ between subtypes, although these samples were small (data not shown).

\section{Adverse events}

Treatment-emergent adverse events were reported in 31 patients $(93.9 \%)$, all of which are summarized in Table 2. Grade 3 or worse adverse events occurred in 23 patients $(69.7 \%)$. Serious adverse events were reported in 18 patients $(54.5 \%)$; the most common serious adverse event was fever $(n=4)$. Other serious adverse events included herpes zoster $(n=2)$, urinary tract infection $(n=1)$, sinusitis $(n=1)$, dyspnea $(n=1)$, diarrhea $(n=1)$, anorexia $(n=1)$, and perianal abscess $(n=1)$. Increase in creatinine was associated with tumor lysis syndrome $(n=1)$. Suicide attempt occurred in one patient (patient 11) after the first cycle; however, the patient was able to continue receiving BV until PD. Patient No. 19's serious adverse event, stroke, led to study discontinuation (Fig. 1). The remaining three patients were admitted to the hospital due to disease progression during the study. The most common adverse events, occurring in $\geq 20 \%$ of patients, included fever $(39 \%)$, neutropenia (30\%), fatigue $(24 \%)$, and peripheral sensory neuropathy (27\%) (Table 2). Gastrointestinal symptoms, including diarrhea, nausea, and vomiting were also commonly observed, and upper respiratory infection, rhinosinusitis, and skin rash were common adverse events in $\geq 10 \%$ of patients (Table 2).

\section{Biomarker analysis for predicting outcome of BV treat- ment}

EBV positivity was not significantly associated with the percentage of CD30 expression in the analysis of 29 patients with available EBV status (Fig. 3A). MUM1 expression was assessed by immunohistochemistry in 24 patients whose tumor tissue was available for study. Nine patients showed negativity for MUM1 (DLBCL 1, PMBCL 1, PTCL 3, and ENKTL 4) whereas the remaining 15 patients were positive for MUM1 (DLBCL 9, PMBCL 2, PTCL 2, and ENKTL 2). MUM1 negativity was more common in 30\%-49\% of CD30 expression whereas MUM1-negative cases were not observed in $80 \%-100 \%$ of CD 30 expression (Fig. 3B). Among nine patients negative for MUM1, five responded to BV (4CR, $1 \mathrm{PR}, 55.6 \%)$, whereas only two responded to BV (1CR, 1PR, $13.3 \%$ ) out of the 15 MUM1-positive patients (Fig. 3C). Although their association with response was not statistically significant $(p=0.061)$, the PFS and OS of MUM1-negative patients were significantly higher compared with MUM1positive patients (Fig. 3D and E). When response was compared based on EBV positivity of tumor cells, using 29 patients with available EBV status, the response to BV among patients with EBV-positive tumor $(35.3 \%, 6 / 17)$ did not differ significantly from those with EBV-negative tumors $(25.0 \%$, $3 / 12 ; p=0.694)$. Accordingly, OS did not differ between EBVpositive and -negative patients $(\mathrm{p}=0.588)$ (Fig. $3 \mathrm{~F})$. 
A

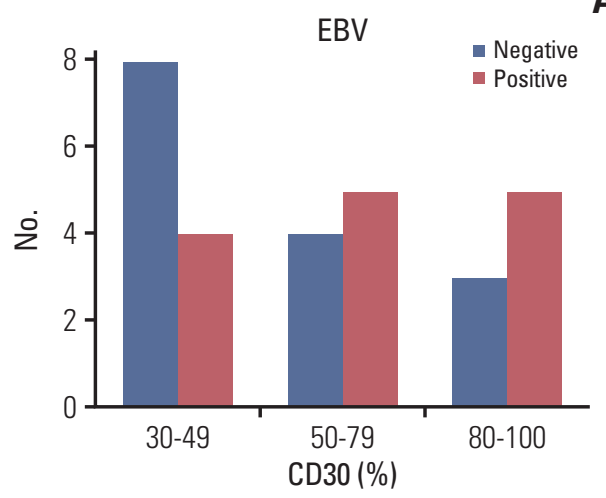

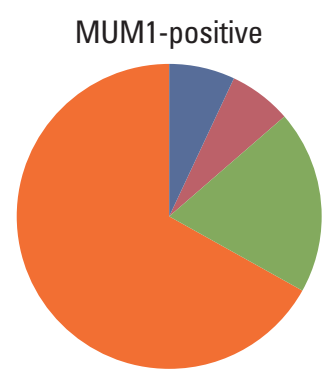

C

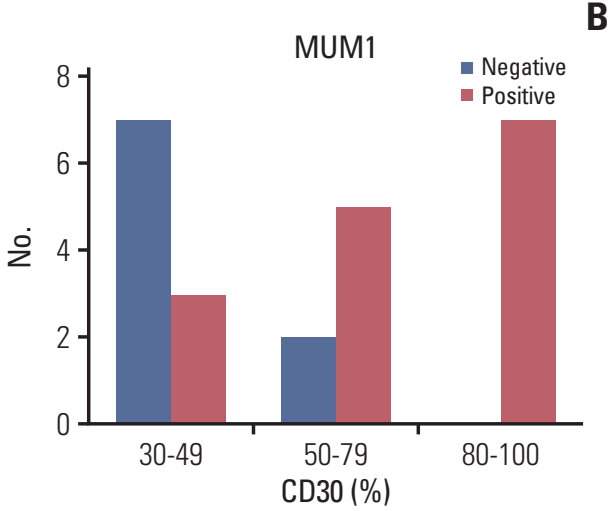

B

$\square \mathrm{CR}$

$\because \mathrm{PR}$

- SD

- $P D$

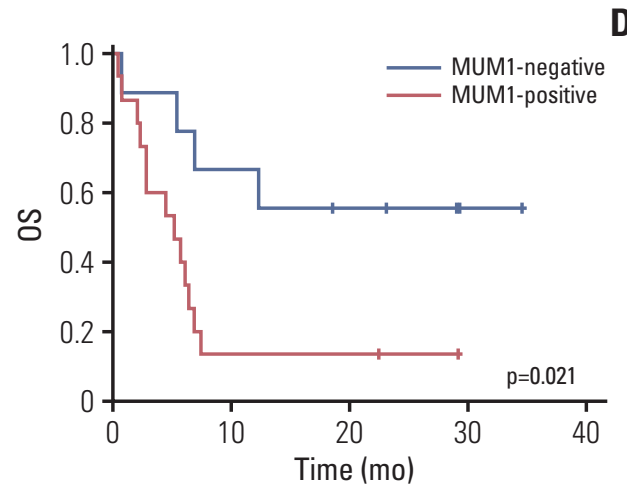

E

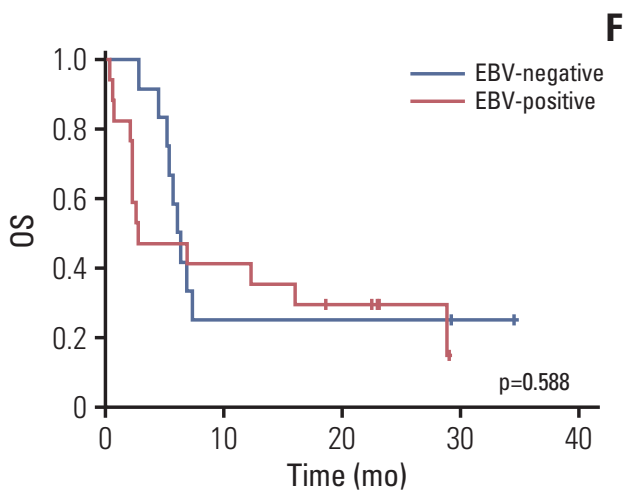

Fig. 3. (A) Epstein-Barr virus (EBV)-positive patients based on percentage of CD30-positive tumor cells. (B) Multiple myeloma oncogene 1 (MUM1)-negative patients based on percentage of CD30-positive tumor cells. (C) Response to brentuximab vedotin by MUM1-negative and -positive patients. (D, E) Overall survival (OS) and progression-free survival (PFS) of MUM1negative and -positive patients. (F) OS of EBV-positive and -negative patients.

\section{Heterogeneity of response}

Patients' best responses could be clearly identified by PET/ CT because patients achieving CR showed complete disappearance of FDG uptake (Fig. 4A and B). However, some patients showed heterogeneous responses of involved sites. For example, one patient with PTCL (patient No. 18) showed PR after the second cycle (Fig. 4C). His remaining target lesions disappeared after the 12th cycle, although new lesions appeared. He continued to receive BV, based on the investigator's decision; however, PD was discovered 2 months after the completion of planned treatment. Two patients (patients Nos. 3 and 4) with DLBCL showed PD after the second cycle of $\mathrm{BV}$, although their responses differed according to the sites involved, with several lesions disappearing and others progressing (Fig. 4D and E). 


\section{A}
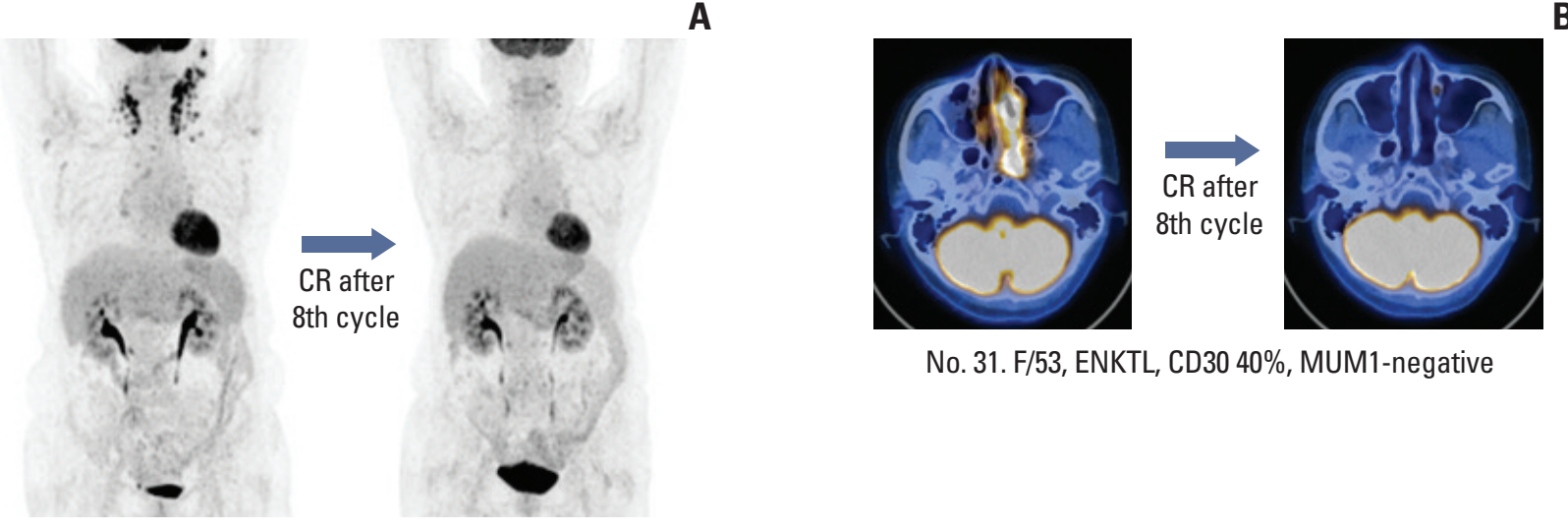

No. 31. F/53, ENKTL, CD30 40\%, MUM1-negative

No. 16. F/69, PTCL, CD30 30\%, MUM1-negative

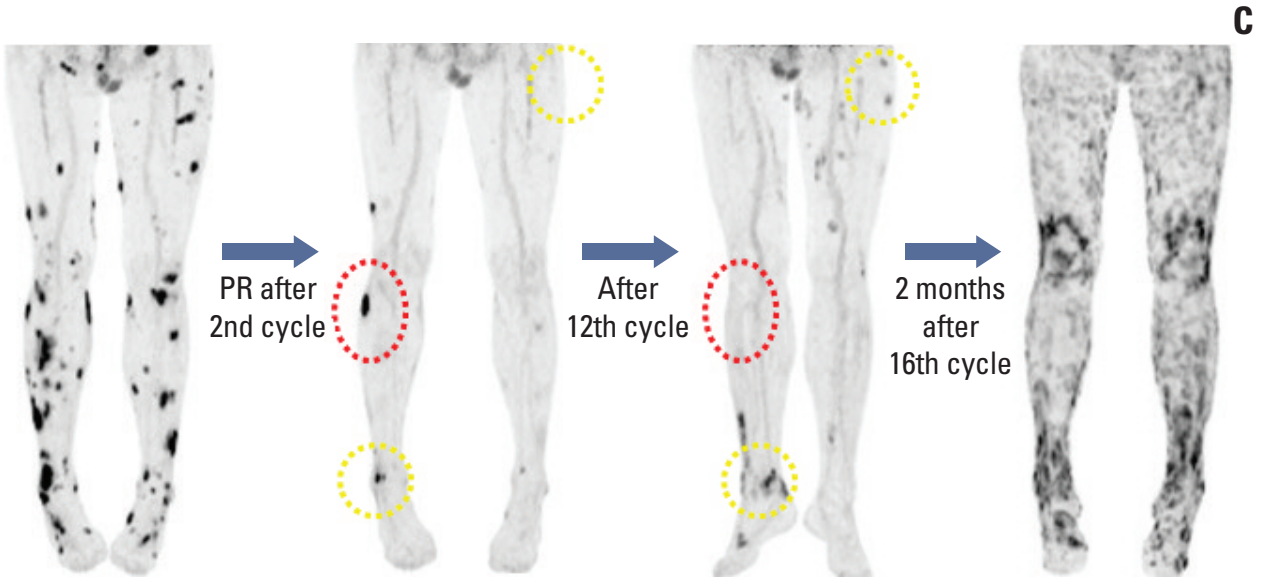

No. 18. M/69, PTCL, CD30 30\%, MUM1-unknown

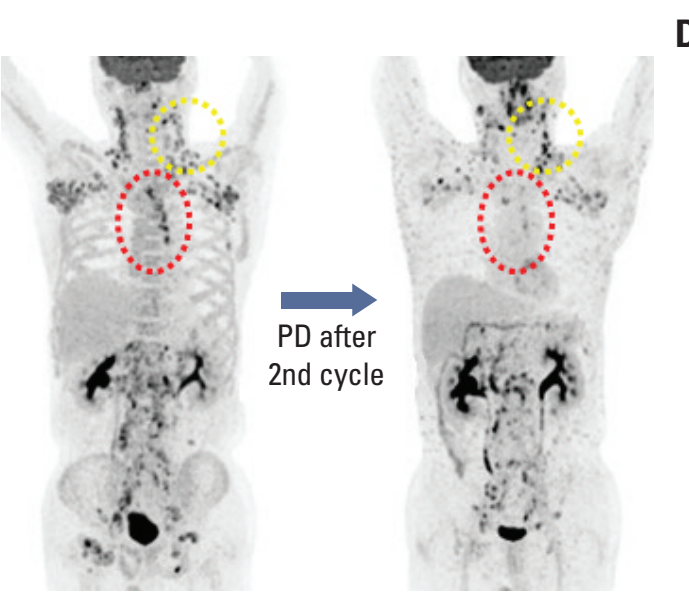

No. 4. M/43, DLBCL, CD30 50\%, MUM1-unknown
D
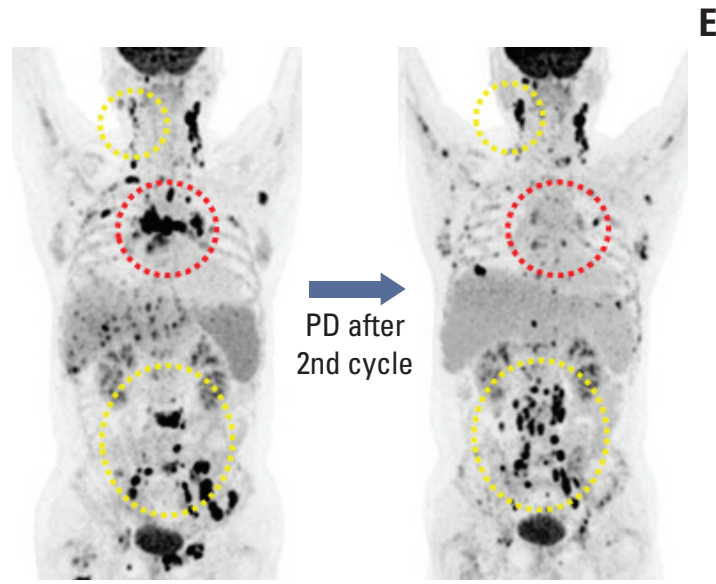

No. 3. M/59, DLBCL, CD30 30\%, MUM1-positive

Fig. 4. (A, B) Patients who achieved complete response (CR) with complete disappearance of fluorine-18 deoxyglucose uptake. (C) Patient with peripheral T-cell lymphoma (PTCL) showing partial response (PR) after the second cycle. His remaining target lesions disappeared after the 12th cycle (red dotted line), although new lesions appeared (yellow dotted line). (D, E) Two patients showed progressive disease (PD) after their second cycle of brentuximab vedotin. Their responses differed based on site because several lesions disappeared (red dotted line) while others progressed (yellow dotted line). MUM1, multiple myeloma oncogene 1; ENKTL, extranodal natural killer/T-cell lymphoma. DLBCL, diffuse large B-cell lymphoma. 
Table 3. Comparison of brentuximab vedotin for relapsed or refractory aggressive non-Hodgkin lymphoma

\begin{tabular}{|c|c|c|c|c|}
\hline Variable & DLBCL [6] & PTCL [7] & PMBCL [8] & Present study \\
\hline No. & 49 & 35 & 15 & 33 \\
\hline Age $(y r)$ & $62(17-85)$ & $64(33-83)$ & $29(19-73)$ & $56(27-73)$ \\
\hline DLBCL-NOS & 43 & - & - & 12 \\
\hline EBV-positive DLBCL & 5 & - & - & - \\
\hline T-cell-rich B cell & 1 & - & - & - \\
\hline PMBCL & - & - & 15 & 3 \\
\hline PTCL & - & 22 & - & 8 \\
\hline AITL & - & 13 & - & 1 \\
\hline ENKTL & - & - & - & 7 \\
\hline Transformed MF & - & - & - & 2 \\
\hline ECOG PS $0 / 1$ & $45(91.8)$ & $30(85.7)$ & Not reported & $33(100)$ \\
\hline $\mathrm{CD}^{+} 0^{+}$cell & $25(0-100)$ & Not reported & Not reported & $30(30-100)$ \\
\hline Stage III/IV & $35(71.4)$ & $27(77.1)$ & $8(53.3)$ & $26(79)$ \\
\hline Refractory to most recent prior therapy & $40(81.6)$ & $22(62.8)$ & $11(73.3)$ & $22(67)$ \\
\hline No. of previous treatments & $3(1-6)$ & $2(1-9)$ & $3(1-4)$ & $3(2-10)$ \\
\hline Previous ASCT & $10(20.4)$ & $3(9)$ & $8(53)$ & $7(21.2)$ \\
\hline Disease control rate & $32 / 48(66.7)$ & $20 / 34(58.8)$ & $3 / 15(20.0)$ & $16 / 33(48.4)$ \\
\hline Objective response rate & $21 / 48(43.7)$ & $14 / 34(41.1)$ & 2/15 (13.3) & $12 / 33(36.3)$ \\
\hline CR rate & $8 / 48(16.7)$ & $8 / 34(23.5)$ & 0 & 6/33 (18.1) \\
\hline Progression-free survival (mo) & $4.0(0.6-24)$ & 2.6 (not reported) & - & $1.9(0.4-35.0)$ \\
\hline Duration of response (mo) & $5.6(0.0-22.7)$ & $7.6(1.3-14)$ & $<3-4$ & $6.0(3.9-35.0)$ \\
\hline Duration of complete response (mo) & $16.6(2.7-22.7)$ & Not reported & - & $11.3(4.5-35.0)$ \\
\hline
\end{tabular}

Values are presented as median (range) or number (\%). DLBCL, diffuse large B-cell lymphoma; PTCL, peripheral T-cell lymphoma; PMBCL, primary mediastinal large B-cell lymphoma; NOS, not otherwise specified; EBV, Epstein-Barr virus; AITL, angioimmunoblastic T-cell lymphoma; ENKTL, extranodal NK/T-cell lymphoma; MF, mycosis fungoides; ECOG PS, Eastern Cooperative Oncology Group performance status; ASCT, autologous stem cell transplantation; CR, complete response.

\section{Discussion}

The study purpose was to determine the overall disease control rate from BV administration among heavily pretreated relapsed or refractory patients with various subtypes of NHL, other than ALCL and HL. Because our study sample was included based on CD30-positive tumor cells being $\geq 30 \%$, regardless of histologic subtype, patients with various subtypes of NHL, from DLBCL to MF, could be enrolled. Considering the study population would be relapsed or refractory patients who were heavily pretreated with intensified cytotoxic chemotherapies, we thought the achievement of SD could be beneficial for those patients who did not have few options for alternative treatment. That was why we designated the overall disease control rate as a primary endpoint instead of objective response rate. Our hypothesis was that CD30 expression-based BV administration would improve the treatment outcome. Although the overall response rate of $36 \%(12 / 33)$ was lower than expected, the overall disease control rate $(48.5 \%, 16 / 33)$ satisfied the primary endpoint
(40\%). Furthermore, six patients maintained their response up to 12 months and could complete the planned number of treatment cycles (Fig. 1A). When our results were compared with that of previous studies for patients with aggressive NHL, the median duration of responders (6.0 months) was comparable to that of previous studies (Table 3). However, the median PFS for all patients (1.9 months) was shorter than that of previous studies with DLBCL (4.0 months), and PTCL (2.6 months), and the different nature of our study population including ENKTL might be associated with relatively poorer outcome than previous studies [6,7]. Although only two patients with transformed MF were enrolled in our study, they all showed PR. This favorable outcome of our study was consistent with the phase III study demonstrating superior efficacy of BV to physician's choice for CD30-positive cutaneous T-cell lymphoma [24]. However, the relatively low response rate of the CD30 expression-based BV administration in our study suggested that the extent of CD30 expression might not predict the response to BV. Thus, the outcome from BV may be independent of CD30 expression in consistent with previous studies. 
There are several potential explanations for this unexpectedly poor outcome among patients with CD30 expression $\geq 30 \%$. First, the immunohistochemistry for CD30 used tumor samples available to the study at patient enrollment. Thus, some patients' samples were from their diagnosis whereas others' were from their point of relapse or progression. Possible changes in CD30 expression from diagnosis to relapse might influence BV-based outcomes. Second, CD30 could be expressed heterogeneously depending on site although we could not perform multiple biopsies in the same patient. If we could evaluate the extent of CD30 expression in different sites of the same patients, the patterns of CD30 expression might differ, possibly leading to different response patterns to BV. Indeed, disease progression was observed even when the target lesion disappeared (Fig. 4). Third, the downregulation of CD30 expression could be related to disease progression during treatment. An in vitro study using the ALCL cell line Karpas-299 showed a reduction in the percentage of CD30-positive cells after long-term BV treatment [25]. Thus, continuous BV treatment may induce downregulation of CD30 expression in tumor cells, leading to drug resistance. In fact, we observed several cases showing disease progression during treatment even though they initially showed response to BV (Fig. 1). Another mechanism of resistance to antibody-drug conjugate is the expression of drug exporter proteins such as multidrug-resistance protein 1 (MDR1) [25]. Because monomethyl auristatin $\mathrm{E}$ is a chemotherapeutic drug affected by MDR1, a drug efflux protein, this may have contributed to the poor outcome from BV seen in this study. Inhibition of MDR1 has been reported to overcome resistance to $\mathrm{BV}$ and show synergism with $\mathrm{BV}$ in a mouse xenograft model [26]. A recent phase I study combining cyclosporine, an MDR1 inhibitor, with BV showed an overall response rate of $67 \%$ (CR 33\%) in primary BV refractory HL patients. These results might support the role of MDR1 in the resistance to BV [27]. Considering that ENKTL tumor cells are well known to express MDR1, the unsatisfactory outcome of ENKTL could be explained by MDR1 expression of tumor cells although we did not evaluate the MDR1 expression of ENKTL patients participating in this study [28].

In a post-hoc analysis to explore biomarkers predicting response to BV, EBV positivity was not significantly associated with the percentage of CD30 expression, whereas MUM1 negativity was more common in 30\%-49\% of CD30 expression, and MUM1-negative cases were not observed in $80 \%$ $100 \%$ of CD30 expression (Fig. 3A and B). This indicates that EBV positivity may be a cause of CD30 expression, although it may not be related to the extent of CD30 expression. However, as MUM1 expression could be activated by CD30 through NF-kB activation, all cases with $>80 \%$ of CD30 expression showed MUM1 positivity while MUM1-negative cases were observed in cases with $<50 \%$ of CD30 expression (Fig. 3B).
Accordingly, EBV positivity was unrelated to response to BV, whereas MUM1 expression showed a tendency toward association with response to BV (Fig. 3C). Furthermore, the OS and PFS of MUM1-negative patients were significantly better than those of MUM1-positive patients (Fig. 3D and E). Given that this analysis was based on 24 patients with DLBCL, PMBCL, PTCL, and ENKTL, which usually follow aggressive courses after relapse, our findings suggest that MUM1 status may serve as a parameter for predicting both response to $\mathrm{BV}$ and survival outcome after BV treatment. Further, our study showed low frequency of MUM1 expression in ENKTL compared with PTCL, which is consistent with our previous study [29]. Thus, the poor response to BV in ENKTL patients of our study might be more related to aforementioned MDR1 expression rather than MUM1 because MDR1 expression is common in ENKTL. However, the association of MDR1 with the response to BV in various subtypes of NHL should be evaluated by additional studies because MDR1 can be expressed and cause resistance to chemotherapy in other subtypes, especially EBV-positive T-cell lymphoproliferative disorders [30].

In this study, the most common adverse events, occurring in $\geq 20 \%$ of patients, included fever (39\%), neutropenia $(30 \%)$, fatigue $(24 \%)$, and peripheral sensory neuropathy $(27 \%)$, which is consistent with previous studies [31,32]. Other side effects, such as gastrointestinal symptoms and upper respiratory infection, were manageable. Although several cases showed central nervous system toxicity and required management, including one suicide attempt after the first cycle, these were all manageable. Thus, the trial's safety profile was comparable with previous experiences with BV and the side effects that occurred were not problematic during treatment, despite our enrollment of heavily pretreated patients with relapsed or refractory lymphomas. This manageable safety profile of BV in relapsed or refractory lymphoma suggested it could be combined with other chemotherapeutic drugs having non-overlapping toxicity. Indeed, a recent phase III study for patients with CD30-positive PTCL showed a significantly improved survival with manageable safety profile in patients receiving the front-line treatment of $\mathrm{BV}$ plus $\mathrm{CHP}$ (cyclophosphamide, doxorubicin, and prednisone) compared to patients treated with $\mathrm{CHOP}$ (cyclophosphamide, doxorubicin, vincristine, and prednisone) [33].

In conclusion, the single-agent activity of BV was acceptable in terms of disease control rate and toxicity profiles in patients with relapsed or refractory high-CD30-expressing NHL. However, administration of BV among patients selected on the basis of CD30 expression did not improve their treatment outcomes compared with previous studies. Outcomes from BV treatment may be independent of CD30 expression, and poor outcome among patients with ENKTL might be related to MDR1 expression of tumor cells. Consid- 
ering the association between improved outcomes in MUM1negative patients irrespective of CD30 expression extent, MUM1 negativity might be a biomarker predicting outcome of BV in CD30-positive lymphomas. Further studies with larger samples are warranted to confirm the results of this phase II study.

\section{Conflicts of Interest}

Conflict of interest relevant to this article was not reported.

\section{Acknowledgments}

We would like to thank the patients, their families and their caregivers who made this study possible. We also thank all the study investigators and study staff at each of the clinical sites. For the CISL, we acknowledge the project manager and all members of the data monitoring committee.

\section{Author Details}

${ }^{1}$ Division of Hematology-Oncology, Department of Medicine, Samsung Medical Center, Sungkyunkwan University School of Medicine, Seoul, ${ }^{2}$ Department of Oncology, Asan Medical Center, University of Ulsan College of Medicine, Seoul, ${ }^{3}$ Division of Hematology, Department of Internal Medicine, Severance Hospital, Yonsei University College of Medicine, Seoul, ${ }^{4}$ Department of Internal Medicine, Korea Cancer Center Hospital, Korea Institute of Radiological and Medical Sciences, Seoul, ${ }^{5}$ Center for Hematologic Malignancy, National Cancer Center, Goyang, 'Department of Pathology, Samsung Medical Center, Sungkyunkwan University School of Medicine, Seoul, ${ }^{7}$ Department of Pathology, Asan Medical Center, University of Ulsan College of Medicine, Seoul, ${ }^{8}$ Department of Pathology, Severance Hospital, Yonsei University College of Medicine, Seoul, ${ }^{9}$ Department of Pathology, National Cancer Center, Goyang, ${ }^{10}$ Department of Pathology, Korea Cancer Center Hospital, Korea Institute of Radiological and Medical Sciences, Seoul, Korea

\section{References}

1. Francisco JA, Cerveny CG, Meyer DL, Mixan BJ, Klussman K, Chace DF, et al. cAC10-vcMMAE, an anti-CD30-monomethyl auristatin E conjugate with potent and selective antitumor activity. Blood. 2003;102:1458-65.

2. Younes A, Gopal AK, Smith SE, Ansell SM, Rosenblatt JD, Savage KJ, et al. Results of a pivotal phase II study of brentuximab vedotin for patients with relapsed or refractory Hodgkin's lymphoma. J Clin Oncol. 2012;30:2183-9.

3. Pro B, Advani R, Brice P, Bartlett NL, Rosenblatt JD, Illidge T, et al. Brentuximab vedotin (SGN-35) in patients with relapsed or refractory systemic anaplastic large-cell lymphoma: results of a phase II study. J Clin Oncol. 2012;30:2190-6.

4. Duvic M, Tetzlaff MT, Gangar P, Clos AL, Sui D, Talpur R. Results of a phase II trial of brentuximab vedotin for CD30+ cutaneous T-cell lymphoma and lymphomatoid papulosis. J Clin Oncol. 2015;33:3759-65.

5. Kim YH, Tavallaee M, Sundram U, Salva KA, Wood GS, Li S, et al. Phase II investigator-initiated study of brentuximab vedotin in mycosis fungoides and Sezary syndrome with variable CD30 expression level: a multi-institution collaborative project. J Clin Oncol. 2015;33:3750-8.

6. Jacobsen ED, Sharman JP, Oki Y, Advani RH, Winter JN, Bello $\mathrm{CM}$, et al. Brentuximab vedotin demonstrates objective responses in a phase 2 study of relapsed / refractory DLBCL with variable CD30 expression. Blood. 2015;125:1394-402.

7. Horwitz SM, Advani RH, Bartlett NL, Jacobsen ED, Sharman JP, O'Connor OA, et al. Objective responses in relapsed T-cell lymphomas with single-agent brentuximab vedotin. Blood. 2014;123:3095-100.

8. Zinzani PL, Pellegrini C, Chiappella A, Di Rocco A, Salvi F,
Cabras MG, et al. Brentuximab vedotin in relapsed primary mediastinal large B-cell lymphoma: results from a phase 2 clinical trial. Blood. 2017;129:2328-30.

9. Hu S, Xu-Monette ZY, Balasubramanyam A, Manyam GC, Visco C, Tzankov A, et al. CD30 expression defines a novel subgroup of diffuse large B-cell lymphoma with favorable prognosis and distinct gene expression signature: a report from the International DLBCL Rituximab-CHOP Consortium Program Study. Blood. 2013;121:2715-24.

10. Hao X, Wei X, Huang F, Wei $Y$, Zeng H, Xu L, et al. The expression of CD30 based on immunohistochemistry predicts inferior outcome in patients with diffuse large B-cell lymphoma. PLoS One. 2015;10:e0126615.

11. Schwartz EJ, Molina-Kirsch H, Zhao S, Marinelli RJ, Warnke RA, Natkunam Y. Immunohistochemical characterization of nasal-type extranodal NK/T-cell lymphoma using a tissue microarray: an analysis of 84 cases. Am J Clin Pathol. 2008; 130:343-51.

12. Li P, Jiang L, Zhang $X$, Liu J, Wang H. CD30 expression is a novel prognostic indicator in extranodal natural killer/T-cell lymphoma, nasal type. BMC Cancer. 2014;14:890.

13. Wright CW, Rumble JM, Duckett CS. CD30 activates both the canonical and alternative NF-kappaB pathways in anaplastic large cell lymphoma cells. J Biol Chem. 2007;282:10252-62.

14. Cao M, Wang Q, Lingel A, Zhang L. Nuclear factor $\kappa B$ represses the expression of latent membrane protein 1 in EpsteinBarr virus transformed cells. World J Virol. 2014;3:22-9.

15. Kim WY, Nam SJ, Kim S, Kim TM, Heo DS, Kim CW, et al. Prognostic implications of CD30 expression in extranodal natural killer/T-cell lymphoma according to treatment modali- 
ties. Leuk Lymphoma. 2015;56:1778-86.

16. Feng Y, Rao H, Lei Y, Huang Y, Wang F, Zhang Y, et al. CD30 expression in extranodal natural killer/T-cell lymphoma, nasal type among 622 cases of mature T-cell and natural killercell lymphoma at a single institution in South China. Chin J Cancer. 2017;36:43.

17. Boddicker RL, Kip NS, Xing X, Zeng Y, Yang ZZ, Lee JH, et al. The oncogenic transcription factor IRF4 is regulated by a novel CD30/ NF- $\mathrm{BB}$ positive feedback loop in peripheral T-cell lymphoma. Blood. 2015;125:3118-27.

18. Shaffer AL, Emre NC, Lamy L, Ngo VN, Wright G, Xiao W, et al. IRF4 addiction in multiple myeloma. Nature. 2008;454:22631.

19. Shaffer AL, Emre NC, Romesser PB, Staudt LM. IRF4: immunity. Malignancy! Therapy? Clin Cancer Res. 2009;15:2954-61.

20. Park S, Kim SJ, Hong JY, Yoon DH, Kim JS, Kang HJ, et al. A phase II study of brentuximab vedotin for relapsed or refractory CD30-positive non-Hodgkin lymphomas other than anaplastic large cell lymphoma. Blood. 2017;130:4077.

21. Cheson BD, Pfistner B, Juweid ME, Gascoyne RD, Specht L, Horning SJ, et al. Revised response criteria for malignant lymphoma. J Clin Oncol. 2007;25:579-86.

22. Simon R. Optimal two-stage designs for phase II clinical trials. Control Clin Trials. 1989;10:1-10.

23. Schemper M, Smith TL. A note on quantifying follow-up in studies of failure time. Control Clin Trials. 1996;17:343-6.

24. Prince HM, Kim YH, Horwitz SM, Dummer R, Scarisbrick J, Quaglino P, et al. Brentuximab vedotin or physician's choice in CD30-positive cutaneous T-cell lymphoma (ALCANZA): an international, open-label, randomised, phase 3, multicentre trial. Lancet. 2017;390:555-66.

25. Chen R, Hou J, Newman E, Kim Y, Donohue C, Liu X, et al. CD30 downregulation, MMAE resistance, and MDR1 upreg- ulation are all associated with resistance to brentuximab vedotin. Mol Cancer Ther. 2015;14:1376-84.

26. Chen RW, Hou J, Nair I, Wu J, Synold T, Kwak LW, et al. Inhibition of MDR1 overcomes brentuximab vedotin resistance in Hodgkin lymphoma cell line model and is synergistic with brentuximab vedotin in mouse xenograft model. Blood. 2016;128:752.

27. Chen RW, Chen L, Herrera AF, Mei M, McBride K, Abary R, et al. Phase 1 study of MDR1 inhibitor plus brentuximab vedotin in relapsed/refractory Hodgkin lymphoma. Blood. 2018; 132:1636.

28. Yamaguchi M, Kita K, Miwa H, Nishii K, Oka K, Ohno T, et al. Frequent expression of P-glycoprotein/MDR1 by nasal T-cell lymphoma cells. Cancer. 1995;76:2351-6.

29. Heo MH, Park HY, Ko YH, Kim WS, Kim SJ. IRF4/MUM1 expression is associated with poor survival outcomes in patients with peripheral T-cell lymphoma. J Cancer. 2017;8:101824.

30. Yoshimori M, Takada H, Imadome K, Kurata M, Yamamoto $\mathrm{K}$, Koyama T, et al. P-glycoprotein is expressed and causes resistance to chemotherapy in EBV-positive T-cell lymphoproliferative diseases. Cancer Med. 2015;4:1494-504.

31. Yi JH, Kim SJ, Kim WS. Brentuximab vedotin: clinical updates and practical guidance. Blood Res. 2017;52:243-53.

32. Oak E, Bartlett NL. A safety evaluation of brentuximab vedotin for the treatment of Hodgkin lymphoma. Expert Opin Drug Saf. 2016;15:875-82.

33. Horwitz S, O'Connor OA, Pro B, Illidge T, Fanale M, Advani $\mathrm{R}$, et al. Brentuximab vedotin with chemotherapy for CD30positive peripheral T-cell lymphoma (ECHELON-2): a global, double-blind, randomised, phase 3 trial. Lancet. 2019;393:22940. 